PSICOLOGÍA

IBEROAMERICANA
Psicología Iberoamericana ISSN: 1405-0943

revista.psicologia@ibero.mx

Universidad Iberoamericana, Ciudad de México México

\title{
Publicación científica y responsabilidad
}

social

Turnbull, Bernardo

Publicación científica y responsabilidad social

Psicología Iberoamericana, vol. 27, núm. 2, 2019

Universidad lberoamericana, Ciudad de México, México

Disponible en: http://www.redalyc.org/articulo.oa?id=133962309006 


\title{
Publicación científica y responsabilidad
}

social

\author{
Bernardo Turnbull bernardo.turnbull@ibero.mx \\ Universidad Iberoamericana, Ciudad de México, México \\ http://orcid.org/0000-0001-9663-913X
}

Psicología Iberoamericana, vol. 27, núm. 2,2019

Universidad Iberoamericana, Ciudad de México, México

Redalyc: http://www.redalyc.org/ articulo.oa?id=133962309006
Tanto la publicación científica como la responsabilidad social son parte de la identidad y misión de nuestra universidad, especialmente en el campo de la psicología.

Por una considerable cantidad de años, el Departamento de Psicología ha asumido esta responsabilidad social integrándola en la formación académica y humana de los alumnos. Las prácticas preprofesionales se han convertido en la columna vertebral de nuestro plan de estudios. En estas prácticas, los alumnos ayudan directamente a quienes no podrían pagar servicios de salud mental. Esto añade una nueva dimensión a la profesión porque ayuda a los estudiantes a conectarse con su comunidad y los problemas sociales críticos que afectan a México. Así, además de dar ayuda directa, los alumnos son capaces de adquirir las habilidades y actitudes necesarias para sobresalir en su profesión como psicólogos, así como una mayor comprensión del significado de la responsabilidad social.

Sin embargo, la psicología es una disciplina científica, y es necesario que incorporemos la responsabilidad social en la forma en que construimos el conocimiento en este campo. Nuestra revista científica, Psicología Iberoamericana, también se suma al compromiso de la universidad con la responsabilidad social. Una revista científica podría desprenderse de tal misión, sin embargo, creemos que reconocer la responsabilidad social y las realidades de los desafíos socioeconómicos a los que se enfrenta México es vital para la creación de conocimiento científico válido en el campo de la psicología. De esta manera, construimos una ciencia que sirve no sólo a sí misma, sino principalmente a la comunidad en general.

Incluso cuando la investigación informa el resultado de las intervenciones psicológicas, esto puede ser interesante pero inútil si no hay implicaciones prácticas de la investigación o el reconocimiento de los desafíos socioeconómicos más amplios y las relaciones de poder en el trabajo implícitas. La ayuda que se da a los profesionales de la ayuda privilegiada hacen dinero, pero eso por sí solo no crea conocimiento que ayude a la mayoría. Debemos buscar una intervención psicológica que parta de la conciencia crítica y, al mismo tiempo, la fortalezca. El reporte científico de este tipo de investigación recupera el sentido humanista de la psicología, al mismo tiempo que pone conocimientos útiles al servicio 
de los verdaderos dueños de los datos, que son las personas de quienes los obtuvimos para investigar y publicar.

Psicología Iberoamericana busca recorrer este camino junto con nuestros profesores y alumnos. Se trata de difundir los conocimientos creados por nuestros profesionales y académicos. Este conocimiento debe ser parte de la formación de nuestro estudiante desde la licenciatura hasta el nivel de posgrado. También es necesario aprovechar las experiencias del programa de prácticas preprofesionales en publicaciones científicas y se difundan con el fin de servir a la comunidad. Nuestra biblioteca tiene tesis doctorales y libros que se centran en este proceso, y todo esto debe contribuir a formar el compromiso social de nuestros estudiantes y perfeccionar sus habilidades. El intercambio de hallazgos de investigación y su posterior disposición con otros profesionales también es beneficioso.

Si nuestro departamento está tratando de poner a los estudiantes en contacto con la realidad de los problemas sociales que afectan a la mayoría de la población en México para construir un sentido de responsabilidad social, entonces nuestra revista busca reunir a los estudiantes y la creación de conocimiento para cerrar el círculo de aprendizaje. 